\title{
UMA REFLEXÃO SOBRE O EMPREGO DOMÉSTICO NO BRASIL: Relações desiguais no mundo do trabalho a partir do gênero
}

\author{
Sueley Luana Silva Inácio ${ }^{1}$ \\ Carmem Lucia Costa ${ }^{2}$
}

\begin{abstract}
RESUMO Compreendemos que uma discussão sobre o emprego doméstico na atual sociedade brasileira não se trata de algo fácil, pois é necessário levar em consideração os processos históricos culturais patriarcais no decorrer dos séculos que se materializam no espaço, desconstruindo algumas relações sociais excludentes arraigadas ao patriarcado e às questões raciais, no sentido de problematizar teoricamente a presença de um grande contingente de mulheres no emprego doméstico. De fato, não é suficiente apenas constatar que o gênero é uma construção social, torna-se necessário reconhecer os diferentes grupos e classes sociais e como o peso do gênero interfere na ocupação de determinadas profissões na sociedade, como o emprego doméstico. Assim, buscamos contribuir para o debate junto a sociedade brasileira e o meio científico, a partir da Ciência Geográfica e seu aparato conceitual metodológico, por meio do artigo UMA REFLEXÃO SOBRE O EMPREGO DOMÉSTICO NO BRASIL: relações desiguais no mundo do trabalho a partir do gênero. Destaca-se que a presente discussão é parte de uma pesquisa desenvolvida no Mestrado em Geografia pela Universidade Federal de Goiás - Regional Catalão concluída no ano de 2016, onde analisamos o trabalho doméstico e os avanços e desafios no início do século XXI para as empregadas domésticas na cidade de Catalão - Goiás. Utilizamos a revisão bibliográfica de alguns autores que discutem sobre trabalho doméstico, espaço e relações patriarcais e de gênero, como: Carrasco (2012), Corrêa (2013), Harvey (1992), Moreira (2015), Ratts (2003), Saffioti (1978), entre outros, na perspectiva de demonstrar, algumas representações sociais que discriminam e excluem determinados sujeitos na sociedade a partir do gênero, raça e cultura, como as(os) empregadas(os) domésticas(os).
\end{abstract}

Palavras-chave: Espaço. Trabalho Doméstico. Gênero.

\section{A REFLECTION ON HOUSEHOLD WORK IN BRAZIL unequal relations in the world of work from the genre}

\begin{abstract}
We understand that a discussion of domestic employment in the current Brazilian society it is not something easy, it is necessary to take into account the patriarchal cultural historical processes over the centuries that materialize in space, deconstructing some social relations exclusive entrenched patriarchy and racial issues, to theoretically discuss the presence of a number of women in domestic employment. In fact, it is not enough to note that gender is a social construction, it is necessary to recognize the different social groups and classes and how gender interferes with the occupation of certain professions in society, such as domestic employment. Thus, we seek to contribute to the debate Brazilian society and the scientific

\footnotetext{
${ }^{1}$ Professora Mestre de Geografia do IFgoiano, Campus Urutai - GO, do ensino tecnico e superior. Membro do Grupo Dialogus - Estudos Interdisciplinares em Gênero, Cultura e Trabalho/UFG/CAC/CNPq.

${ }^{2}$ Professora Doutora da Universidade Federal de Goiás - Regional Catalão/UFG/CAC - Departamento de Geografia/Programa de Pós - Graduação em Geografia/UFG/CAC/Membro do grupo Dialogus - Estudos Interdisciplinares em Gênero, Cultura e Trabalho/UFG/CAC/CNPq.
} 


\section{ITMERARUS \\ REFLECTIONIS}

Volume, 13, n.2, Ano, 2017

community, from the Geographic Science and its methodological conceptual apparatus through this text A REFLECTION ON HOUSEHOLD WORK IN BRAZIL: unequal relations in the world of work from the genre. This discussion is part of a research developed in the Masters in Geography from the Federal University of Goiás - Regional Catalão completed in the year 2016, where we analyze the domestic work and the progress and challenges in the early twenty-first century to the maids. In Catalão - Goiás, we used some literature review of some authors who discuss domestic labor, space and patriarchal relations and gender, as Carrasco (2012), Correa (2013), Harvey (1992), Moreira (2015), Ratts (2003), Saffioti (1978), among others. In order to demonstrate some social representations that discriminate and exclude certain individuals in society from the gender, race and culture, such as employed domestic.

Keywords: Space. Housework. Genre.

\section{INTRODUÇÃO}

Há séculos vários grupos sociais lutam por um espaço na sociedade, seja no mercado de trabalho, nas universidades, acesso à moradia, por igualdade de gênero, raça e cultura. Entre tantos que merecem reconhecimento e abordagem das Ciências Humanas estão as empregadas domésticas, que realizam um trabalho fundamental na reprodução da vida, principalmente nas cidades. Dentre estas ciências, está a Geografia.

Nessa perspectiva, utilizamos a Ciência Geográfica e o espaço urbano para demonstrar os cenários de exclusão em que as(os) trabalhadoras(es) domésticas(os) estavam inseridas(os) no decorrer da história no Brasil, vislumbrando a luta das(os) trabalhadoras(es) pelo reconhecimento de seus direitos trabalhistas e sociais no espaço geográfico brasileiro.

Cabe destacar que o trabalho doméstico pode ser realizado por qualquer pessoa no âmbito do espaço privado ou público. No entanto, se o(a) empregador(a) patrão(oa) decidir contratar alguém para prestar serviço de caráter doméstico no espaço privado mediante um contrato de trabalho e remuneração, este passa a ser, então, um emprego doméstico, o que configura o recorte desse presente artigo.

De acordo com a Cartilha do Trabalhador Doméstico do Ministério de Trabalho e Emprego, integram a categoria de empregados(as) domésticos(as): cozinheiro(a), governanta, babá, lavadeira(or), faxineiro(a), vigia, motorista particular, acompanhante de idosos, jardineiro(a) e caseiro(a).

Todavia, mesmo abrangendo várias funções, conforme o Instituto Brasileiro de Geografia e Estatística - IBGE (2014), o trabalho doméstico “[...] é essencialmente feminino no Brasil, o contingente de mulheres corresponde a 92\% (5.973 milhões) sendo 62\% negras e 
Volume, 13, n.2, Ano, 2017

pardas com pouca escolaridade". Estes dados nos motivam a pesquisar porque o trabalho doméstico no Brasil tem a cara da mulher e aparece como lugar de mulher negra e pobre.

Além da contribuição científica, este artigo tem o propósito de conscientizar a população de que o trabalho doméstico é uma atividade de indiscutível relevância para a sociedade brasileira.

2 O TRABALHO DOMÉSTICO NO BRASIL: Histórico de discriminação a partir do gênero e da raça.

Desde o período de colonização, a relação com o trabalho doméstico no Brasil é um campo das mulheres, principalmente, das negras escravas e, depois, das ex-escravas. As mulheres brancas do Brasil colônia, doutrinadas sob os valores da Igreja Católica, realizavam alguns afazeres domésticos, como pintar, bordar, entre outros trabalhos que lhes dariam o título de boas esposas. A esse respeito, Saffioti (2013) afirma que:

\footnotetext{
A tradição cultural de que eram portadores os europeus aliada à escassez de mulheres brancas e à licenciosidade dos costumes explicam a reclusão a que os homens obrigavam suas filhas e esposas durante o período colonial. O princípio da segregação sexual, integrante da tradição ibérica e validado pela Igreja Católica, iria, assim, pesar profundamente na formação da personalidade feminina, fazendo da mulher um ser sedentário, submisso, religioso, de restrita participação cultural. (SAFFIOTI, 2013, p. 267).
}

Nesse contexto, a autora explica o lugar da mulher no Brasil colônia, o que nos permite afirmar que homens e mulheres tiveram papéis sociais diferenciados no decorrer da história. Foram as relações patriarcais que submeteram as mulheres ao espaço privado, sendolhes legadas exclusivamente as obrigações domésticas.

Desde crianças, as mulheres eram preparadas para serem boas donas de casa e esposas submissas. Conforme Souza (2013, p.135), "muito disso se deve à concepção bíblica de que a primeira mulher, Eva, surgiu de uma parte do homem, Adão", assim, ela "seria, pois, subordinada ao homem".

É certo que tal visão religiosa alimentou a concepção de que a mulher era inferior ao homem, restringindo a participação da mesma no espaço público, diretamente relacionado às decisões de âmbito político, econômico e social. Dessa maneira, as mulheres no Brasil 


\section{TTMEPARUS REFLECTIONIS}

Volume, 13, n.2, Ano, 2017

colônia eram oprimidas por meio de alguns valores impostos pela Igreja Católica e discriminadas pelos homens.

Vale explicitar que as mulheres negras escravas, além de serem discriminadas, eram inferiorizadas em relação à mulher branca, sofriam vários tipos de violência em meio à sociedade patriarcal.

Nesse contexto, Ratts (2003, p. 04 - 05) explica que havia uma hierarquia no Brasil colônia: "Em primeiro lugar situa-se o homem branco; em segundo, a mulher branca; em terceiro, o homem negro; e, por último, a mulher negra". Ademais, entre as mulheres negras, havia uma divisão entre mucamas e escravas da senzala, embora, ambas desempenhassem trabalhos domésticos.

As mucamas eram jovens e bonitas. Eram mais bem tratadas que as demais escravas em relação às vestimentas e à alimentação, visto que valiam mais, normalmente, cuidavam das crianças, acompanhavam e zelavam da aparência das sinhás-moças e eram amas de leite, sendo obrigadas a dividir o leite de seus filhos(as) com as(os) filhas(os) das senhoras. As escravas da senzala, por sua vez, eram destinadas a alguns trabalhos domésticos de limpeza e organização.

Com a Lei do Ventre Livre, em 1872, e a Abolição dos Escravos, em 1888, há o fim do regime escravocrata no Brasil e então surgem novas modalidades de exploração da força de trabalho no espaço geográfico brasileiro. Segundo Moreira (2015):

[...] através da troca do trabalho escravo pelo de uma diversidade de formas de trabalho rural nas quais um mecanismo de assalariamento se combina com a manutenção da velha relação binominal de monocultura-policultura, e com a mesma função de transferir, agora totalmente, para a massa trabalhadora, a tarefa de gerar os meios com que cuidará de produzir sua própria força de trabalho. (MOREIRA, 2015, p.87).

Sob esta ótica, molda-se uma nova estrutura econômica na sociedade brasileira, na qual, gradativamente, a mão de obra escrava negra foi sendo substituída pelo trabalho assalariado do imigrante europeu, branco, nas lavouras agrícolas brasileiras, que, em sua maior parte, eram extensas plantações de café. Dessa forma, o Brasil, aos poucos, passou por um processo de miscigenação entre as(os) negras(os), índias(os) e europeus.

Cabe destacar que, no início, as(os) trabalhadoras(es) imigrantes eram de origem europeia, o que reforçava ainda mais no território brasileiro a estrutura e organização patriarcal da família, em que a mulher realizava trabalhos doméstico e nas lavouras. 
Volume, 13, n.2, Ano, 2017

Quanto à nova forma de exploração do trabalho, Saffioti (2013, p. 57) considera que "a remuneração do trabalho em dinheiro, portanto, sob a forma de salário, disfarça a apropriação, por parte do capitalista [...]". Nesse sentido, o trabalho assalariado afirma a liberdade das(os) trabalhadoras(es) e disfarça a exploração da força de trabalho.

No que se refere à realidade dos(as) ex-escravos(as) no Brasil, Souza (2013) relata:

\begin{abstract}
A situação dos negros "agraciados" com a liberdade não era muito melhor do que aquela vivida na escravidão. Desqualificados para o trabalho, analfabetos, muitos deles enfrentaram uma dura realidade: trocar sua mão de obra por comida e, quando muito, alguma vestimenta e local para morar (SOUZA, 2013, p. 138, grifo do autor).
\end{abstract}

Alguns(mas) ex-escravos(as), habitualmente analfabetos(as), sem qualificação para trabalharem nas indústrias manufatureiras na cidade, mantiveram-se nas fazendas em que trabalhavam, de forma que seu trabalho era negociado em troca de alimentação e moradia.

Cabe evidenciar que a troca da força de trabalho pela necessidade de sobrevivência também se reproduz na cidade, o que nos leva a refletir sobre a origem do trabalho doméstico em casas de famílias na quais as empregadas domésticas moravam.

Nesse contexto, também havia alguns(mas) negros(as) que conseguiram migrar para as cidades e foram morar nos piores locais (cortiços insalubres) e trabalhar em subempregos (trabalhos informais e manuais), o que reforçou a segregação socioespacial no espaço urbano. A respeito da discriminação que os negros e as negras sofriam no Brasil pósabolicionista, Souza (2013) ratifica que:

\footnotetext{
A discriminação que sofriam os negros, e muito mais ainda as negras, no Brasil pósabolição, resulta, sobretudo, na ideia etnocêntrica de que os brancos eram superiores aos negros. Com a liberdade dada aos escravos negros, a parcela branca dominadora da sociedade sentia a necessidade de manter uma "certa distância". (SOUZA, 2013, p.131, grifos do autor).
}

De fato, este discurso etnocêntrico contribuiu para a desigualdade social no Brasil no decorrer dos séculos. Sob a desigualdade de oportunidades e a discriminação, as ex-escravas sofreram mais, por serem mulheres, negras e pobres.

Tendo em vista compreender a realidade das negras no Brasil após a escravidão, destacamos um trecho da obra "Símbolo e alegorias do preconceito: uma leitura do conto 'Maria Caboré",, de Ronaldo Correia de Brito, na qual Souza (2013) faz uma leitura sobre a história de uma jovem mulher negra: 
Volume, 13, n.2, Ano, 2017

\begin{abstract}
Ao ser pilado, o cereal tem sua casca separada do restante da semente, o que reforça a idéia de discriminação. A parte considerada útil e nobre, a semente, é representante da parcela branca da sociedade, ao passo que a outra parte, a casca, considerada de pouca utilidade e, muitas vezes, descartada, representa a parcela negra. $\mathrm{O}$ pilão, portanto, é um instrumento de discriminação, já que separa a casca do arroz de seu grão, duas partes de um mesmo elemento, tão intrinsecamente ligados e tão necessários um ao outro e à manutenção de sua própria espécie. Maria Caboré, que tinha muitas atividades, era também lavadeira. Simbolicamente, a lavadeira pertence a uma casta inferior até às prostitutas, já que estas são consideradas mais necessárias à sociedade do que aquelas. Maria era tratada como inferior e era, inclusive, motivo de chacota. (SOUZA, 2013, p.133).
\end{abstract}

Esta é uma de muitas obras literárias que descrevem a discriminação vivenciada por mulheres negras no final do século XIX, fruto de construções históricas de uma sociedade capitalista patriarcal, que se utilizava de relações raciais, de gênero e divisão de classes para explorar da forma mais perversa a força de trabalho de alguns(mas) trabalhadores(as), principalmente, mulheres.

Nesse contexto de discriminação e desigualdade social, na necessidade de sobrevivência, as(os) negras(os) libertas(os) foram trabalhar como mascates, quitandeiras(os), vendedoras(es) ambulantes, empregadas(os) domésticas(os) e em outras atividades sem qualquer espécie de direitos. Eram trabalhos considerados desprestigiados, manuais e de pouco valor na sociedade capitalista. Quanto ao trabalho doméstico, Lopes (2008) destaca que:

\begin{abstract}
Após a abolição da escravatura, as empregadas negras foram (temporariamente) substituídas em peso por empregadas européias, porém segundo Koffes (2001), a preferência por empregadas brancas é permeada de ambigüidades, pois havia a preferência pelo corpo - aparência - da empregada branca e pela corporeidade da empregada negra, acarretando uma ruptura simbólica, ou seja, a desigualdade entre patroa e empregada, ambas brancas, se limita à condição deste ser a que obedece, que executa o serviço doméstico; já a empregada doméstica negra, em função de sua corporeidade, suscita representações sociais vinculadas ao escravismo - continuidade simbólica - demonstrando que persistia no imaginário social a idéia de que uma "boa empregada doméstica" - submissa, servil, etc. - deveria ser negra, portanto já estava estabelecida a associação entre negra (escravizada) e trabalhadora doméstica. (LOPES, 2008, p. 65, grifo da autora).
\end{abstract}

De acordo com a autora, embora a força de trabalho feminina europeia se fazesse presente na sociedade brasileira no decorrer dos anos, a construção social da mulher negra ao trabalho servil sustentou a permanência de muitas trabalhadoras brasileiras em trabalhos precários e desvalorizados pela sociedade, como o emprego doméstico. 
Volume, 13, n.2, Ano, 2017

Do ponto de vista da exploração do trabalho, outra atividade de labor degradante, assumida por muitas mulheres negras após a abolição da escravatura, foi a prostituição. Sobre este trabalho, Saffioti (2013) aponta que:

Nos primeiros tempos após a abolição, internaria também no processo de prostituição a degradação moral a que tinha sido reduzida a mulher negra. Desmistificava-se, entretanto, como a universalização do salariato, o fundamento econômico da prostituição. (SAFFIOTI, 2013, p.252).

Por motivo econômico e de sobrevivência, muitas mulheres negras foram submetidas à prostituição assalariada, considerada um trabalho degradante na sociedade capitalista patriarcal.

Sobre o racismo e a desvalorização que ocorria na sociedade brasileira no final do século XIX, Nascimento et al. (2012) esclarecem que:

\begin{abstract}
O Brasil no século XIX foi fortemente influenciado pelas teorias científicas de cunho racista, nos quais vários cientistas estrangeiros e brasileiros acreditavam, defendiam e propagavam a ideia de que a raça negra era inferior à branca. Esse ideal foi incorporado na política de Estado do início da república, quando o governo provisório liderado pelo chefe de governo Marechal Deodoro da Fonseca comandou uma série de decretos, no qual um desses, tratava da regulamentação da entrada e localização de imigrantes no país, sendo que, os indivíduos de origem africana e asiática necessitavam de autorização do Congresso Nacional para desembarcarem em portos brasileiros. (NASCIMENTO et al., 2012, p. 43).
\end{abstract}

Eram intelectuais da elite brasileira que defendiam o branqueamento da população, que, consequentemente, impulsionaram as práticas racistas e a inferiorização da cultura afro-brasileira, disseminando na sociedade a concepção de que a desigualdade entre homens e mulheres, brancos e negros era algo natural.

Destarte, construía-se um discurso puritano que desvalorizava os costumes, como dança, religião, comida e vestimenta das(os) negras(os) brasileiras(os). A ideologia de que a cultura branca era superior à negra foi tão propagada que, inclusive, alguns(mas) negros(as) começaram a reproduzir tal discurso, adotando a educação e o estilo de vida dos homens e das mulheres da classe dominante.

Percebe-se, ante tanta discriminação, que o fim da escravidão não veio para corrigir as injustiças contra as(os) negras(os) no Brasil, e sim como uma dinâmica de fomento ao modo de produção capitalista. Para Carrasco et al. (2012): 
Volume, 13, n.2, Ano, 2017

O capitalismo entrou rompendo os velhos sistemas de produção e os foi substituindo por uma tímida exploração capitalista que não permitia ocupar e dar bem-estar a todos os que eram expulsos dos atrasados sistemas tradicionais de produção. Portanto, produziu miséria dolorosa, desemprego crônico e estrutural, superexploração, analfabetismo, níveis alarmantes de prostituição. (CARRASCO et al., 2012, p. 36).

É nesse cenário de desigualdade e exploração que o capitalismo se reconfigurou no espaço geográfico brasileiro. Até a metade do século XX, a população brasileira rural era maior que a urbana, todavia, após este período, o Brasil passou por uma era de modernização na agricultura e na indústria. Dessa forma, as relações capitalistas de produção foram se territorializando no campo e na cidade, o que resultou em maior concentração fundiária e de renda. O pequeno produtor foi expropriado, acentuando o processo migratório para as cidades, na quais o fenômeno da industrialização estava em vigor. Do ponto de vista geográfico, Harvey (2005) contribui:

Evidentemente, o capital e a força de trabalho devem se unir em algum ponto específico do espaço para ocorrer a produção. A fábrica é um ponto de reunião, enquanto a forma industrial de urbanização pode ser vista como a resposta capitalista específica à necessidade de minimizar o custo e o tempo do movimento sob condições da conexão interindústrias, da divisão social do trabalho e da necessidade de acesso tanto à oferta de mão-de-obra como aos mercados dos consumidores finais. Os capitalistas individuais, em virtude de suas decisões localizacionais específicas, moldam a geografia da produção em configurações espaciais distintas. (HARVEY, 2005, p. 146).

Em consonância com o autor, a intervenção capitalista traz mudanças espaciais expressivas, tanto no campo quanto na cidade. De modo mais contundente, a força de trabalho é integrada à cidade, modificando alguns valores cotidianos das(os) trabalhadoras(es).

Assim, após 1960, no Brasil, o êxodo rural acelerou um processo de urbanização que acontecia sem um devido planejamento, o que deu origem às favelas e bairros periféricos desprovidos de infraestrutura. Corrêa $(2013$, p.46) observa que "[...] na periferia das cidades localizam-se os loteamentos populares, as favelas e precários conjuntos habitacionais, onde reside uma população de baixo status". É nestes espaços que a população pobre, em sua maioria negra e com uma parcela considerável de mulheres, mora.

Segundo Saffioti (1978, p.14), a "redução substancial da população economicamente ativa no campo e incremento nas cidades", na década de 1960, no Brasil, a "melhora do nível de renda" e o "drástico incremento dos membros da população 


\section{ITTEERARUS \\ REFLECTIONIS}

Volume, 13, n.2, Ano, 2017

economicamente ativa que apresentam educação de nível superior" fazem aparecer uma nova classe média de assalariados consumistas. E salienta que:

Se, de um lado, assiste-se a um incremento da procura de bens duráveis de consumo, por outro, expande-se o consumo de serviços pessoais, notadamente o doméstico. Desta forma, uma parte considerável da força de trabalho que não é absorvida pela grande empresa acaba por se colocar a serviço da "nova" classe média (e também da alta) como empregadores domésticos, lavadores e guardadores de carros, jardineiros [...]. (SAFFIOTI, 1978, p. 14-15).

Assim, há mudanças na esfera social e econômica da população brasileira no decorrer dos anos. De fato, além das fábricas captarem a mão de obra feminina nos segmentos mais precários da produção, a nova classe média brasileira absorve um acentuado percentual de mulheres nos empregos domésticos, uma mão de obra barata. Portanto, algumas mulheres se inserem no mercado de trabalho fabril, ultrapassando a condição de isolamento no espaço privado a que estavam submetidas

Todavia, se por um lado a mulher consegue se inserir no espaço público mediante o mercado de trabalho que lhe proporciona melhores condições econômicas, por outro lado, ainda lhe são atribuídas as atividades domésticas do lar, consideradas, no seio da sociedade capitalista, trabalho não produtivo.

Nesse sentido, muitas trabalhadoras passaram a desempenhar duplas jornadas de trabalho. Isto significa que, além da sociedade brasileira patriarcal capitalista oprimir as mulheres, também as explora, perpetuando a visão de que o trabalho doméstico do âmbito familiar é encargo da mulher.

Entretanto, percebe-se que o labor de estar no mercado de trabalho e, ao mesmo tempo, exercer atividades domésticas no lar, dependerá da classe social à qual a mulher pertence, visto que ela pode remunerar outra trabalhadora para realizar os trabalhos domésticos.

Logo, existem relações sociais de poder e subordinação entre as mulheres, isto é, entre patroas e empregadas. Ou seja, apesar de todas as mulheres terem sido inferiorizadas e desvalorizadas em relação ao homem na sociedade patriarcal, existe um padrão hierárquico de poder entre as mulheres a partir da classe social e da raça em que elas se inserem.

Contudo, devemos visualizar que, mesmo que algumas mulheres não desempenhem trabalhos domésticos no âmbito da sua residência, tais afazeres são transferidos a outra mulher. Portanto, o trabalho doméstico continua sendo exercido, em grande parte, por mulheres. 
Volume, 13, n.2, Ano, 2017

Dessa forma, percebe-se que, no decorrer das décadas, o cenário de desvalorização da força de trabalho feminina continua. Mesmo havendo uma participação mais expandida da mulher no mercado de trabalho, em maior parte, tratam-se de atividades laborais de baixa remuneração, com precárias condições e relações de trabalho, como o emprego doméstico. Nessa perspectiva, Harvey (2011) afirma que:

[...] diferenças emergem como fundamentais para o funcionamento do mercado de trabalho. Tornam-se ferramentas por meio das quais os capitalistas administram a oferta de trabalho em conjunto com os setores privilegiados da força de trabalho que usam o racismo e o machismo para minimizar a competição. (HARVEY, 2011, p. 57).

Portanto, o capital se utiliza das relações raciais e de gênero construídas historicamente para intensificar a exploração da força de trabalho da classe trabalhadora, o que agrava a questão social de grupos no espaço geográfico brasileiro. Ante a isto, reconhecemos a desigualdade que afeta as trabalhadoras domésticas desde o período escravocrata no Brasil, inicialmente, um trabalho servil e, posteriormente, um trabalho de baixa remuneração.

Em consonância com este debate, Lopes (2008) acrescenta que:

[...] acreditamos que uma das justificativas para a histórica subalternização e desvalorização do emprego doméstico no Brasil (além do quase universal desprestígio sociocultural do mesmo no mundo por ser um serviço de mulher e não-produtivo), está vinculado à questão racial, isto é, em função do elo de continuidade que o emprego doméstico representa entre a sociedade colonial e a contemporânea, levando à desvalorização social do trabalho doméstico e daquelas que o realizam predominantemente mulheres, pobres e em sua maioria negras e pardas - por meio da manutenção e transmissão de representações sociais negativas - algumas apenas reelaboradas - referentes à natureza do trabalho doméstico - servil, sujo, aviltante, etc. - e de quem o desempenha - acomodado, burro, etc. - passadas de geração a geração, de dominantes para dominantes, vividas e sentidas por gerações de dominados. (LOPES, 2008, p. 57).

Em síntese, a autora demonstra a continuidade da desvalorização social do emprego doméstico e das trabalhadoras na sociedade contemporânea. Assim, reconhecemos que esta geração de dominantes e dominados(as) pode ser compreendida a partir da discussão de classe na sociedade capitalista, levando em consideração as desigualdades construídas socialmente a partir do gênero e da raça no espaço geográfico brasileiro.

Mediante esses relatos de desigualdade e inferiorização, torna-se instigante compreender a luta e os enfrentamentos das(os) empregadas(os) domésticas(os) no decorrer da história em busca de igualdade e reconhecimento de seus direitos. 


\section{ITTEERARUIS \\ REFLECTIONIS}

Volume, 13, n.2, Ano, 2017

Nessa perspectiva, compreendemos que, hoje, a empregada doméstica é tida como íntima, a que compartilha o cotidiano da casa e da família, esfera em que o poder do Estado não pode regular e, portanto, os direitos e deveres de ambas as partes se apresentam de forma confusa.

Sobre a desvalorização que as trabalhadoras domésticas sofriam no século XX no Brasil, Pinto (1993, p. 312), em sua pesquisa, evidencia o relato de uma trabalhadora: "Se a gente quer comprar uma roupa nova não pode porque não tem crédito nas lojas. Aí a patroa vai, faz o crediário e desconta do salário da gente".

Com o propósito de análise, apresentamos, também, a fala de umas das trabalhadoras pesquisadas na cidade de Catalão (GO) no século XXI pela autora Silva (2016, p.53): "A minha patroa me libera mais cedo quando tenho que levar meus filhos no médico e sempre que preciso me deixa comprar remédios na sua conta, é difícil alguém abrir conta para uma trabalhadora como eu quem nem tem carteira assinada. (ANITTA, 2015)".

Por meio dos dois relatos, percebemos a relação informal com a qual a empregada doméstica é tratada na sociedade, tanto no século XX quanto no XXI, e as diferentes formas de exploração que se escondem por detrás da 'amizade' e da 'ajuda'. É certo que tais ajudas poderão ser cobradas pelas(os) empregadoras(es) com alguns serviços extras no final do expediente.

Esta falta de reconhecimento profissional e econômico na sociedade capitalista segregou as(os) empregadas(os) domésticas(os) em alguns espaços de grande concentração de pobreza e vulnerabilidade social nos bairros de periferia nas cidades brasileiras.

Os territórios são ocupados a partir das relações econômicas das(os) trabalhadoras(es) no espaço. Sobre isto, Corrêa (2013, p.43) afirma que: "A segregação residencial das classes subalternas resulta também de uma política de classe, gerada por aqueles que detêm poder, controlando diferentes meios de produção".

De modo geral, importa reconhecer que as(os) empregadas(os) domésticas(os) integram a classe dos sujeitos que sofrem com a miséria, desigualdade e discriminação que permeiam o Brasil. A respeito da discriminação e do estereótipo que se fazem presentes na sociedade brasileira sobre as empregadas domésticas, Lopes (2008) expõe que:

Na sociedade brasileira contemporânea são vários os mecanismos que reificam e evidenciam a persistência das representações sociais negativas - preconceituosas referentes ao universo do trabalho doméstico feminino - associada principalmente à questão racial, a moral e ao baixo nível cultural das trabalhadoras: meios de 


\section{TTTEPRARUS \\ REFLECTIONIS}

Volume, 13, n.2, Ano, 2017
REVISTA ELETRÔNICA

DA GRADUAÇÃ O/PÓS - GRADUAÇÃO EM EDUCAÇÃ O

comunicação em massa - televisão - por meio da divulgação de filmes, novelas, campanhas publicitárias - principalmente as referentes a produtos de limpeza - que veiculam uma imagem estereotipada da empregada doméstica - negra, fofoqueira, maledicente, brega, ladra, as que se submetem as investidas sexuais dos membros masculinos da casa, etc. (LOPES, 2008, p. 60).

Os meios de comunicação de massa, por meio de produções midiáticas, como novelas, filmes etc., produzem valores que reforçam as construções sociais desiguais no Brasil. Assim, o estereótipo negativo da empregada doméstica produzido pela mídia reforça a subalternidade e discriminação da mulher trabalhadora doméstica e a desvalorização do emprego doméstico em relação às demais ocupações profissionais.

De fato, não podemos deixar de destacar que após 513 anos de história no Brasil e 25 anos de criação da Constituição Federal Brasileira de 1988, as(os) empregadas(os) domésticas(os) conquistaram alguns direitos que já eram de outras(os) trabalhadoras(es) de diversos postos de trabalho, mediante a Emenda Constitucional $\mathrm{n}^{\circ}$ 72, conhecida inicialmente como $\mathrm{PEC}^{3}$ das Domésticas ou PEC n⿳ 66/2013. Esta, de fato, corrobora para a ampliação dos direitos já adquiridos na Lei $\mathrm{n}^{\mathrm{o}} 5.859 / 72$, assegurando à categoria das(os) empregadas(os) domésticas(os) direitos decorrentes da relação de trabalho e suas peculiaridades.

Assim, em 02 de abril de 2013, foi promulgada a Emenda Constitucional $n^{\circ} 72$, alterando o artigo $7^{\circ}$ da Constituição Federal de 1988. Os direitos expressos nessa Emenda que foram ampliados às(aos) domésticas(os) são: "VII - garantia de salário mínimo, X - proteção salarial, constituindo crime a sua retenção dolosa, XIII - duração do trabalho normal não superior a oito horas diárias e quarenta e quatro semanais facultadas à compensação de jornada, XVI hora extra de 50\%, XXVI - reconhecimento e acordos coletivos de trabalho (sindicatos), XXX proibição da discriminação salarial por motivo de sexo, idade, cor ou estado civil, XXXI proibição de discriminação ao portador deficiente, XXXIII - proibição do trabalho noturno, perigoso e insalubre a menor de 18 anos e de qualquer trabalho a menor de 16 , salvo como menor aprendiz a partir de 14 anos”, conforme a Presidência da República.

No sentido de fazer valer a Emenda Constitucional nº72, em 09 de abril de 2014, foi aprovada a Lei $n^{\circ} 12.964 / 14$ que pune o patrão/patroa que não assinar a carteira de trabalho da(o) profissional com uma multa no valor de $\mathrm{R} \$ 805,06$ reais. Este valor não vai para o bolso

\footnotetext{
3 PEC das Domésticas significou Proposta de Emenda Constitucional n ${ }^{\circ}$ 66/2013 que culminou na Emenda Constitucional $n^{\circ} 72 / 2013$, acrescentando direitos na Constituição aos trabalhadores(as) domésticos(as). Alguns destes com eficácia plena e outros com eficácia limitada - pendente de regulamentação mediante Lei Complementar.
} 


\section{TTMEPARUS \\ REFLECTIONIS}

Volume, 13, n.2, Ano, 2017

da(o) empregada(o), e sim para os cofres do Governo Federal, ficando estipulado ao empregador(a) o prazo de 48 horas para o registro da carteira de trabalho.

Vale salientar que assinar a carteira de trabalho da(o) empregada(o) doméstica(o) é uma ação obrigatória desde 1972, ou seja, este direito vem sendo desrespeitado há 42 anos, se considerada a porcentagem de trabalhadoras(es) sem carteira assinada, com variação entre 23,3\% a 46,4\%, dependendo da região no Brasil, de acordo com a Pesquisa de Emprego e Desemprego (PED), publicada em abril de 2015, sobre o emprego doméstico.

Conjunto a tais dados é necessário enfatizar que, no Brasil, o maior contingente de trabalhadoras(es) que ocupa o emprego doméstico, consoante o Instituto de Geografia e Estatística (IBGE), na Pesquisa Mensal de Emprego (PME) publicada em fevereiro de 2014, compõe-se de “[...] mulheres, correspondendo a $92 \%$, sendo $62 \%$ pretas e pardas ${ }^{4}$, com pouca escolaridade".

Diante desse quadro, confirmamos que a baixa escolarização, a divisão de classe, gênero e raça são fatores que caracterizam a sociedade capitalista, que tem sua reprodução baseada na exclusão social e espacial, o que explicaria, de fato, a exploração das empregadas domésticas no início de século XXI.

De tal modo, reconhecemos que, apesar de alguns avanços legislativos, a herança colonial patriarcal brasileira continua a segregar e marginalizar as(os) empregadas(os) domésticas(os), que são, em grande parte, mulheres.

\section{CONSIDERAÇÕES FINAIS}

Ao analisar a evolução histórica do empregado doméstico no Brasil e a motivação do reconhecimento tardio dos direitos das(os) empregadas(os) domésticas(os), notamos que a sociedade brasileira é machista e sexista. Com efeito, a violência contra o gênero feminino também se oculta na exploração da força de trabalho e na posição das mulheres em comparação à posição dos homens no mercado de trabalho.

Mesmo após séculos, o emprego doméstico no Brasil é uma atividade laborativa predominantemente feminina, de ordinário, associada à figura da mulher submissa, zelosa e com pouca escolaridade. As relações capitalistas de produção se apropriam desta construção

\footnotetext{
${ }^{4}$ Pardo é mais usado pelo IBGE para se referir às(aos) brasileiras(os) com variadas ascendências raciais, seja essa miscigenação mulata descendente de brancos e negros, cabocla descendente de brancos e ameríndios, cafuza ou mestiça descendente de negros e indígenas.
} 


\section{ITINERARIUS \\ REFLECTIONIS}

Volume, 13, n.2, Ano, 2017

social baseada na desigualdade de gênero para desvalorizar o emprego doméstico e explorar a trabalhadora. De fato, no modo de produção capitalista, a mulher se situa em ocupações mal remuneradas e desprestigiadas.

Desta feita, reconhecemos que existem avanços na legislação brasileira com o propósito de mudar as relações de desigualdades de direitos trabalhistas entre as(os) empregadas(os) domésticas(os) e as demais categorias de trabalhadoras(es).

Todavia, a promulgação da Emenda Constitucional $n^{\circ} 72$, que amplia os direitos as(os) empregadas(os) domésticas(os), e a Lei n ${ }^{\circ} 12.964 / 14$, que multa as(os) empregadoras(es) que não assinarem a carteira das(os) trabalhadoras(es), não são suficientes para erradicar as desigualdades e a desvalorização do trabalho doméstico na atual sociedade.

Destaca-se, que a vulnerabilidade econômica das(os) empregadas(os) domésticos(as) e as barreiras socioculturais engendram a segregação socioespacial destas trabalhadoras na cidade, condicionando-as a uma vida modesta, com baixa qualidade de vida, e a privações no uso e apropriação do espaço urbano.

Portanto, este artigo tem objetivo de conscientizar a população da relevância do trabalho doméstico na sociedade, de modo a minimizar a desvalorização e a discriminação socialmente construídas em relação às empregadas domésticas.

\section{REFERÊNCIAS}

BRASIL. Consolidação das Leis do Trabalho - CLT. Disponível em: <http://www.planalto.gov.br/ccivil_03/decreto-lei/Del5452.htm>. Acesso em: 13 de junho de 2014.

Constituição da República Federativa do Brasil. Brasília-DF: Senado Federal: Centro Gráfico, 1988. 292 p.

Ministério do Trabalho e Emprego. Cartilha do trabalhador doméstico. Disponível: <http://portal.mte.gov.br/trab_domestico/trabalho-domestico.htm>. Acesso em: 18 de junho de 2014.

CARRASCO, Carmem. PETIT, Mercedes. Mulheres trabalhadoras e marxismo. Um debate sobre opressão. O capitalismo, a família e a opressão da mulher. São Paulo: Editora Instituto José Luis e Rosa Sundermann, 2012.

CORREAA, Roberto Lobato. Segregação Residencial: classes sociais e espaço urbano. In: A cidade Contemporânea segregação espacial. (Org.) VASCONCELOS, P. de A.; CORRÊA, R. L. e PINTAUDI, S. M. São Paulo: Contexto, 2013. 
Volume, 13, n.2, Ano, 2017

DIEESE. Pesquisa Emprego Doméstico. Disponível em: <http://www.dieese.org.br/ estudosetorial/2013/est Pesq68empregoDomestico.pdf>. Acesso em: 04 de maio de 2015.

Pesquisa Emprego Doméstico. Disponível em: <http://www.dieese.org.br/analiseped /2014/2014 EmpregoDomestico.pdf>. Acesso em: 05 de maio de 2015.

HARVEY, David. A produção capitalista do espaço. São Paulo: Editora Annablume, 2005.

O enigma do capital: e as crises do capitalismo. Tradução de João Alexandre Peschanki. São Paulo: Editora Boitempo, 2011.

IBGE. Pesquisa Mensal de Emprego PME: algumas das principais características dos Trabalhadores Domésticos vis a vis a População Ocupada. Disponível em: <http://www.ibge.gov.br/home/estatistica/indicadores/trabalhoerendimento/pme_nova/princ_ carac_trab_dom.pdf $>$. Acesso em: 18 de junho de 2014.

LOPES, Renata Batista. De casa para outras casas: trajetórias socioespaciais de trabalhadoras domésticas residentes em Aparecida de Goiânia. Dissertação (Mestrado em Geografia) apresentada junto ao Instituto de Estudos Socio-Ambientais da Universidade Federal de Goiás. Goiânia-GO: 2008.

MOREIRA, Ruy. O que é geografia. 5ed. São Paulo: Brasiliense, Primeiros Passos, 2015.

FILHO, Guimes Rodrigues. OLIVEIRA, Cristiane Coppe de. NASCIMENTO, João Gabriel do. O pensamento branco de João Batista Lacerda e suas consequências: Brasil 1911-2011. In: Formação inicial, História e cultura africana e afro-brasileira: desafios e perspectivas na implementação da Lei Federal 10.639/2003. (Org.) FILHO, G. R. et al. 1ed. Uberlândia-MG: Editora Gráfica Lopes, 2012.

PINTO, Elisabete Aparecida. Etnicidade, Gênero e Educação: a trajetória de vida de D. Laudelina de Campos Mello (1904 - 1991). Dissertação (Mestrado) apresentada junto a Universidade Estadual de Campinas, Faculdade de Educação. Campinas-SP: 1993.

RATTS, Alecsandro. Gênero, raça e espaço: trajetórias de mulheres negras. Comunicação apresentada n 27. In: Encontro Anual da ANPOCS. Caxambu-MG: 2003.

SAFFIOTI, Heleieth Iara Bongiovani. A mulher na sociedade de classes. Mito e realidade. 3ed. São Paulo: Editora Expressão Popular, 2013.

Editora Vozes, 1978.

Emprego Doméstico e Capitalismo. Petrópolis-RJ:

SANTOS, Gabriela Silva dos. Significados atribuídos ao trabalhador: uma análise comparativa entre professores no ensino superior em diferentes regimes de trabalho. Faculdade de Ciências Empresariais. Belo Horizonte-MG: 2010. 


\section{ITINERARIUS REFLECTIONIS}

REVISTA ELETRÔNICA

DA GRADUAÇÃ O/PÓS-GRADUAÇÃO EM EDUCAÇÃ O

Volume, 13, n.2, Ano, 2017

SILVA. Sueley Luana da. TRABALHO DOMÉSTICO: avanços e desafios no início do século XXI para as empregadas domésticas na cidade de Catalão - Goiás. Dissertação (Mestrado em Geografia) apresentada junto ao Programa de Pós-Graduação em Geografia e Ordenamento do Território pela Universidade Federal de Goiás - Regional Catalão, 2016.

SOUZA, Carlos Santana de. Gênero, linguagens e etnicidades. Símbolos e Alegorias do preconceito: Uma leitura do conto "Maria Caboré, de Ronaldo Correia de Brito. (Org.) BORGES, L. et al. Goiânia-GO: FUNAPE, 2013. 